Industrial Health, 1979, 17. 61.

\title{
A NEW DIRECT METHOD FOR COLORIMETRIC DETERMINATION OF HIPPURIC ACID AND METHYLHIPPURIC ACID AS INDICES OF TOLUENE AND m-XYLENE, AND ITS APPLICATION TO WORKERS USING THINNER
}

\author{
Masana OGATA and Tatsuya HOBARA $\dagger$ \\ Department of Public Health, Okayama University Medical School, \\ Shikata-cho, Okayama 700, Japan \\ $\dagger$ Department of Public Health, Yamaguchi University, School of Medicine, \\ Ube 755, Japan.
}

(Received July 16, 1979)

A new accurate direct colorimetric method by p-dimethyl-aminobenzaldehyde (DAB) for determining the concentration of urinary hippuric acid and methylhippuric acids as indices of toluene or xylenes exposure was devised by us.

To $0.02 \mathrm{ml}$ of urine containing hippuric acid, $2.0 \mathrm{ml}$ of $0.4 \%$ DAB solution in pyridine and $1.0 \mathrm{ml}$ of acetic anhydride were added, and the solution was kept at $30^{\circ} \mathrm{C}$ for $1 \mathrm{hr}$. after thoroughly mixing. Then, the absorbance was determined at $460 \mathrm{~nm}$. against a blank solution containing acetic anhydride, DAB and pyridine and water instead of urine.

This direct and sensitive colorimetric method for the determination of hippuric acid in urine is applicable to the concentrations under at least $2.0 \mathrm{mg} / \mathrm{ml}$ of water or urine according to Beer-Lowbert law.

The variation coefficient in the determination of hippuric acid by this method was small ranging from 1.3 to $2.7 \%$, and the recovery was between 100.5 and $104.8 \%$ when a urine sample contained about $1.0-2.0 \mathrm{mg}$ hippuric acid per $\mathrm{ml}$ of the urine. In the present paper, moreover, normal value of urinary hippuric acid determined by this method is described.

As on application of this new method, urinary hippuric acid and methylhippuric acids in the urine of six workers in shipbuilding yard, who used paint thinner containing both toluene and $m$-xylene, were determined.

Toluene and xylenes are widely used as organic industrial solvents. Toluene administered to animals is first oxidized to benzoic acid, which conjugates with glycine to form hippuric acid. According to E1 Masry, Smith and Williams (1956), about $75 \%$ of the toluene administered to rabbits is excreted as hippuric acid. Thus it appears likely that most of the toluene inhaled by workers will also be excreted into the urine as hippuric acid, so the quantitative estimation of toluene inhaled to each worker should be done by the determination of hippuric acid in the urine. Only a previous check on 


\section{OGATA AND T. HOBARA}

this suggestion was carried out by von Oettingen, Nieal and Donahue (1942), who determined urinary hippuric acid of volunteers exposed to toluene over $100 \mathrm{ppm}$ in their laboratory. However, they used a crystallization-titration method which is not sensitive enough for the quantitative analysis of urinary hippuric acid from workers exposed to small amounts of toluene.

Xylene, or dimethylbenzene, has three isomers, o-, $\mathrm{m}-$, and $\mathrm{p}$-xylene, and the mixture is commonly called xylol, boiling in the range of $135-145^{\circ} \mathrm{C}\left(275-295^{\circ} \mathrm{F}\right)$. A typical xylene derived from coal tar consists of $15 \%$ ortho-, $53 \%$ meta-, $23 \%$ para-xylene, and $6 \%$ ethylbenzene. A typical petrochemical commercial xylene consists of approximately $20 \%$ ortho-, $44 \%$ meta-, $20 \%$ para-xylene, and $15 \%$ ethylbenzene. Commercial xylene may contain traces of the following chemicals: toluene, phenol, thiophene, pyridine and non-aromatic hydrocarbons.

In this paper, a convienient and reproducible method based on colorimetry is presented. Many papers in respect of the determination method of hippuric acid (HA) have been published. These methods depend on column chromatography, ${ }^{1)}$ thin-layer chromatography,2) paper chromatography,,$^{3)}$ fluorometry,4) gas chromatography, ${ }^{5,}{ }^{6)}$ titration, ${ }^{7)}$ and the determination of radioactivity. ${ }^{8)}$

The method used most widely at present is based on high performance liquid chromatography (HLC).

Two colorimetric methods have been presented for the determination of HA. In the method of Umberger, ${ }^{9}$ ) which was later modified by Ogata, the color is produced in a mixture of the HA-containing sample with benzenesulfonyl chloride (BSC) and pyridine. In the method reported by Gaffney et $a l^{3)}$ and Ogata et $a l,{ }^{10)}$ the color is produced in a mixture of the HA-containing sample with DAB and pyridine. Gaffney et al employed paper chromatography. They detected the HA spot developed on a paper by spraying $4 \%$ solution of $\mathrm{DAB}$ in acetic anhydride which contained a few crystals of sodium acetate with subsequent heating of the chromatogram at $130-150^{\circ} \mathrm{C}$ for 1-2 min. The absorbance of the color was determined after elution of the spot. Ogata et al improved this method and their reaction mixture of DAB was added to dried silica gel containing ethylacetate extract and heated at $135^{\circ} \mathrm{C}$ in an oil bath.

A few years ago, Tomokuni and Ogata introduced a direct colorimetric method using BSC which eliminated the extraction process. ${ }^{11)}$ This method was simpler than the other procedure in past reports, but some variation were found in the value from a sample, and the recovery was relatively low. Recently, an improved method for direct determination using BSC reaction, was devised by Ogata and Sugihara. ${ }^{12}$ Upon the method, determination error was minimized and recovery rate was improved. Thereafter authors described a new method of colorimetric determination of HA using DAB and this method was applied for dried samples extracted from biological materials such as hemolysates. ${ }^{13)}$

This paper reports a new direct colorimetric method, which uses DAB and pyridine. This method is more accurate than BSC method for the determination of urinary HA 


\title{
DIRECT COLORIMETRIC METHOD OF HIPPURIC ACID
}

or methylhippuric acid (MHA).

\author{
Material AND Methods
}

\section{Materials}

All reagents used were of reagent grade. HA standard solution $(5.0 \mathrm{mg} / \mathrm{ml})$, and MHA standard solution: Dissolve $500 \mathrm{mg}$ of hippuric acid (Merk Chemical, Rahway, N. J. 07165) in water and diluted to $100 \mathrm{ml}$ in a glass-stoppered volumetric flask. Dissolved $539 \mathrm{mg}$ of $\mathrm{m}-$, p-, and o-methylhippuric acid (Nihon-Kankoshikiso Co.) in water and diluted to $100 \mathrm{ml}$ in a glass-stoppered volumetric flask.

Urine samples were collected from workers in a ship building yard. In the yard, six workers are employed for painting works such as spraying or painting by hands of paint, which is diluted suitably with thinner containing toluene and m-xylene, on to the wall of cabins and bottoms of ships.

Urine samples were taken from workers. Urine of these workers were first collected from 6.00 to 8.30 a.m., then from 11.00 a.m. to 12.00 noon, and finally from 4.30 p.m. to 5.00 p.m., and these were classified as urine before, during, and after working respectively. HA and MHA were determind by the direct colorimetric method described below.

\section{Methods}

a) Extraction of $H A$ from urine.

The original method for determing $\mathrm{HA}$ in homogenate was used. Urine $(0.1 \mathrm{ml})$, $10 \mu 1,6 \mathrm{~N} . \mathrm{HCl}$, ca. $20 \mathrm{mg} \mathrm{NaCl}$ and $1 \mathrm{ml}$ ethyl acetate in a $10 \mathrm{ml}$ test tube were mixed for $30 \mathrm{sec}$. with a Vortex Mixer. (Thermonics Inc. Japan.) After $5 \mathrm{~min}, 0.1 \mathrm{ml}$ of the ethyl acetate layer was transferred to a $20 \mathrm{ml}$ test tube and evaporated to dries under reduced pressure.

b) Development of colour and its measurement.

i) Extraction $\mathrm{DAB}$ method.

To the dried sample containing $\mathrm{HA}, 1.0 \mathrm{ml}$ of acetic anhydride and $2.0 \mathrm{ml}$ of $0.5 \%$ $\mathrm{DAB}$ solution in pyridine were added in turn. After mixing thoroughly, the solution was kept at $40^{\circ} \mathrm{C}$ for $1 \mathrm{hr}$. The absorbance was then measured at $458 \mathrm{~nm}$ against a blank containing acetic anhydride, DAB and pyridine.

The Model DK-2A ratio-recording spectrophotometer (Beckman Instruments Corp., Fullerton Calif. 92634) and Hitachi Perkin-Elmer 139 spectrophotometer (Perkin-Elmer Corp. Norwalk. Conn. 06852) were used.

ii) New accurate direct method with $\mathrm{DAB}$ and pyridine (Direct DAB method).

To $0.02 \mathrm{ml}$ of urine containing $\mathrm{HA}, 2.0 \mathrm{ml}$ of $0.4 \% \mathrm{DAB}$ solution in pyridine and $1.0 \mathrm{ml}$ of acetic anhydride were added in turn. After mixing thoroughly, the solution was kept at $30^{\circ} \mathrm{C}$ for $1 \mathrm{hr}$. The absorbance was then measured at $460 \mathrm{~nm}$ against a blank containig pyridine, DAB and acetic anhydride. 


\section{OGATA AND T. HOBARA}

iii) Improved BSC method.

Method of Ogata et al was used. ${ }^{12)}$

c) High performance liquid chromatography. ${ }^{15)}$

The method of Ogata and Sugihara for the determination of urinary glycine conjugates was applied to HLC.

d) Thin-layer chromatography.

Thin-layer chromatography was carried out using the method of Ogata et al. ${ }^{16)}$

Silica gel plate was scratched off at $1 \mathrm{~cm}$ interval from original line to front on the thin-layer chromatography. Each section was extracted with $2 \mathrm{ml}$ and $1 \mathrm{ml}$ of pyridine successively, and the each extracts were colored by adding $1 \mathrm{ml}$ of $0.8 \% \mathrm{DAB}$ in pyridine and $1 \mathrm{ml}$ of acetic acid. The absorption spectrum was measured using a 100-50 double-beam spectrophotometer of Hitachi Company.

e) Determination of thinner concentrations in the air. ${ }^{17)}$

i) Sampling tube for adsorption. (room air sampler).

Stainless steel column, sized $7.6 \mathrm{~cm}(1) \times 4 \mathrm{~mm}$. (id) was used as the sampling tube. In the tube, $0.18 \mathrm{~g}$ of Porapack $\mathrm{Q}$ or $0.1 \mathrm{~g}$ of TENAX GC was filled. Then, both ends were plugged with glass wool.

ii) Desorption of organic solvents from the sampling tube.

The adsorpt vapour in the sampling tube was released as vapour by heating at $200^{\circ} \mathrm{C}$ for $1 \mathrm{~min}$ in Bendix Model H/S 10, Flasher, and then the vapour was introduced into a gas chromatograph.

iii) Gas chromatographic condition.

Apparatus; Hitachi 063 (attachment FID).

Column; Chromosorb. W. $\beta \beta^{\prime}$-TDPN $20 \%, 2 \mathrm{~m}$ stainless steel column,

Oven temp.; $90^{\circ} \mathrm{C}$, Carrier gas; $\mathrm{N}_{2} 40 \mathrm{ml} / \mathrm{min}$.

\section{RESULTS}

1) Time course of colour development of $H A$ when the method described in [b)-ii)] was used.

As shown in Fig. 1, it takes about $1 \mathrm{hr}$ at $30^{\circ} \mathrm{C}$ for obtaining the maximun colour with $\mathrm{HA}$ in water, and the colour is stable for at least $30 \mathrm{~min}$.

2) Absorption spectra of standard solution.

Absorption spectra obtained with $\mathrm{HA}$ in water $(1.0 \mathrm{mg} / \mathrm{ml})$ and o-, $\mathrm{m}-, \mathrm{p}-\mathrm{MHA}$, in water $(1.0 \mathrm{mg} / \mathrm{ml}$, respectively) by method described already in the item [b)-ii)] of the material and method (Fig. 2). The maximum absorbance at $458-460 \mathrm{~nm}$ was obtained when the concentration ratio of pyridine to acetic anhydride was 2 as described in the previous report. ${ }^{13)}$ The values of molecular extinction coefficient of $\mathrm{HA}$ and m-MHA were nearly equal and higher than those of $\mathrm{p}$-, o-MHA. 


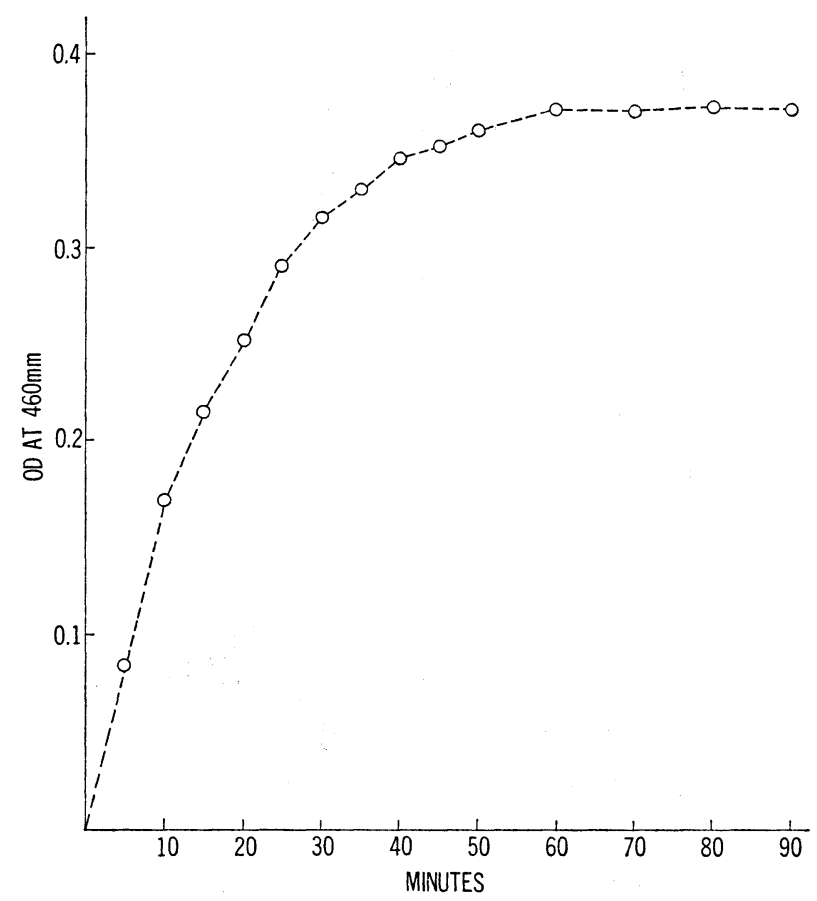

Fig. 1. Time course of color development of HA (20 $\mu \mathrm{g}$ in $0.02 \mathrm{ml}$ water). The reaction mixture was as follows: $0.02 \mathrm{ml}$ sample, $2.0 \mathrm{ml}$ of $0.4 \% \mathrm{DAB}$ solution in pyridine and $1.0 \mathrm{ml}$ of acetic anhydride at $30^{\circ} \mathrm{C}$.

3) Calibration curve and reproducibility.

The calibration curve obtained by using a water solution of HA was linear within the range from 0.5 to $2.0 \mathrm{mg} / \mathrm{ml}$ as shown in Fig. 3 .

Calibration curves of MHAs were also shown in Fig. 3.

This new method was considered to be precise enough for the measurement of HA because of the low values of variation coefficient being in the range of $1.3-2.7 \%$. The values of variation coefficient of $\mathrm{o}^{-}, \mathrm{m}-$, and $\mathrm{p}-\mathrm{MHA}$ were $1.5-3.0 \%, 1.3-2.7 \%$, and $1.5-$ $2.9 \%$, respectively.

As indicated in Fig. 3, the calibration curve of HA in urine, into which HA was added, was linear and showed a little high optical density compared with that of HA in water, though urine sample itself without the addition of HA showed some light absorbance which derived to intrinsic HA. The same result was observed on MHA in water, though the details were not illustrated. The value of $\mathrm{HA}$ or MHA at $460 \mathrm{~nm}$ by the new method showed $94 \%$ of that at $410 \mathrm{~nm}$ by improved BSC method in water solution. Therefore, analytical sensitivily of direct DAB method is similar to BSC method (Table 1). 
M. OGATA AND T. HOBARA

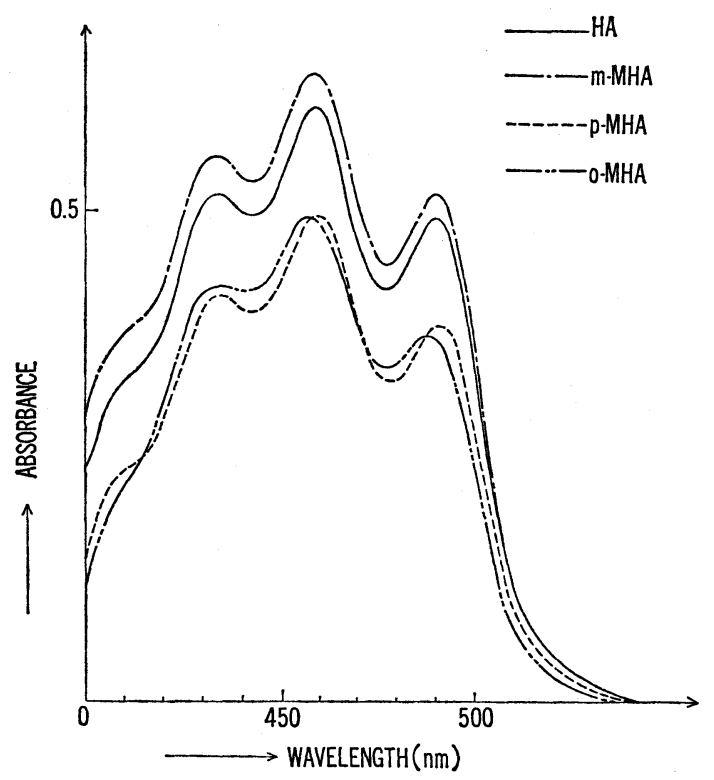

Fig. 2. Absorption spectra of HA, m-MHA, p-MHA, and o-MHA, maximum at $458-460 \mathrm{~nm}$. HA, m-, o-, and p-MHA (20 $\mu \mathrm{g}$ in $0.02 \mathrm{ml}$ water), respectively, was reached with $0.4 \% \mathrm{DAB}$ solution in pyridine and acetic anhydride at $30^{\circ} \mathrm{C}$ for $1 \mathrm{hr}$.

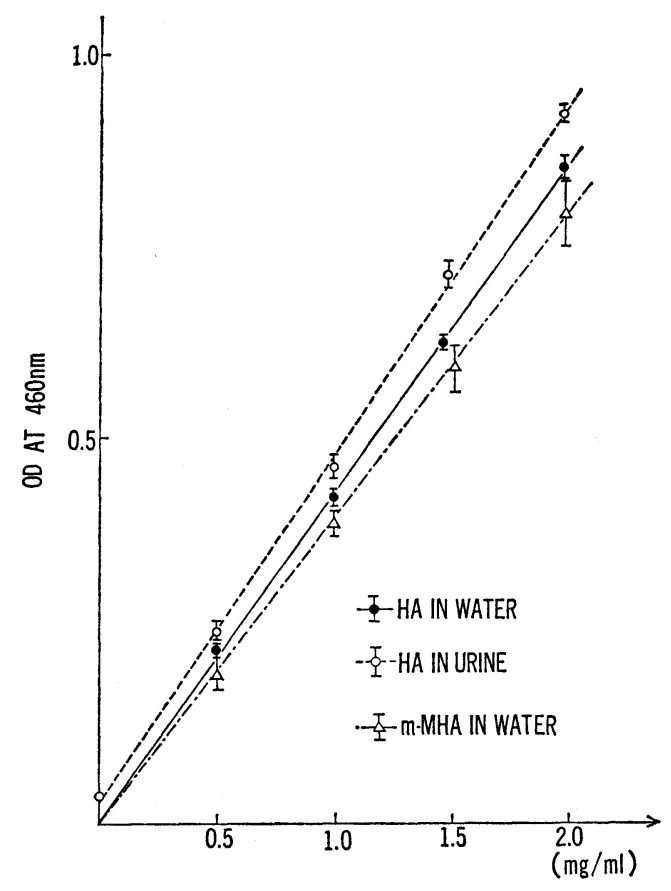

Fig. 3. Calibration curves of HA in water and in urine and $\mathrm{m} \cdot \mathrm{MHA}$ in water. 


\section{DIRECT COLORIMETRIC METHOD OF HIPPURIC ACID}

Table 1. Mean values, standard deviation of error and variation coefficient with HA in various concentrations by DAB or BSC method, respectively.

\begin{tabular}{|c|c|c|c|c|c|}
\hline \multirow{2}{*}{\multicolumn{2}{|c|}{$\overbrace{\text { method }}^{\text {conc. }}$}} & \multicolumn{4}{|c|}{ water volume added $(\mathrm{ml})$} \\
\hline & & 0.5 & 1.0 & 1.5 & 2.0 \\
\hline \multirow{3}{*}{$\mathrm{DAB}$} & mean & 0.23 & 0.42 & 0.64 & 0.85 \\
\hline & SEM & 0.0036 & 0.0047 & 0.0047 & 0.0109 \\
\hline & varia. coeff. & $\begin{array}{l}2.7 \\
(1.2) *\end{array}$ & $\begin{array}{r}1.9 \\
(26)^{*}\end{array}$ & $\begin{array}{r}1.3 \\
(12)^{*}\end{array}$ & $\begin{array}{r}2.2 \\
(65)^{*}\end{array}$ \\
\hline \multirow{3}{*}{$\mathrm{BSC}$} & mean & 0.24 & 0.4 & 0.66 & 1.01 \\
\hline & SEM & 0.024 & 0.017 & 0.041 & 0.02 \\
\hline & varia. coeff. & 17.3 & 7.3 & 10.7 & 3.4 \\
\hline
\end{tabular}

Unit, $\mathrm{mg} / \mathrm{ml}$, * parenthesis shows the ratio as percent of variation coefficient in DAB method to BSC method. coefficient variation; $(\mathrm{SD} /$ mean $) \times 100$.

As shown in Table 2, the values of recovery percentage corresponding to the addition of $1.0,1.5$, and $2.0 \mathrm{mg} / \mathrm{ml}$ of $\mathrm{HA}$ into urine were about $101.5,104.5$, and $102.4 \%$ by this DAB method. Moreover, similar results were obtained with m-MHA.

Table 2. Recoveries of HA added to urine

\begin{tabular}{cccc}
\hline HA added $\dagger$ & exp. 1 & exp. 2 & average (\%) \\
\hline 1.0 & 0.98 & 1.05 & 101.5 \\
1.5 & 1.016 & 1.08 & 104.8 \\
2.0 & 1.00 & 1.047 & 102.4 \\
\hline
\end{tabular}

$\uparrow$ Concentration of $\mathrm{HA}(\mathrm{mg} / \mathrm{ml})$ added to urine.

4) Comparison between the value of urinary $H A$ measured by the direct $D A B$ method and that by the extraction DAB method. ${ }^{13}$

Urine samples from 12 persons with no occupational exposure to toluene or m-xylene in this laboratory were examined. The corrected mean value of HA concentration with the specific gravity of normal urine, 1.024 , was $0.02 \mathrm{mg}$ per $\mathrm{ml}$ of urine by the direct $\mathrm{DAB}$ method. The regression equation in respect of $\mathrm{HA}$ value obtained by the extraction $\mathrm{DAB}$ method $(\mathrm{Y})$ is expressed as $\mathrm{Y}=0.78 \mathrm{X}-0.005$, where $\mathrm{X}$ shows the $\mathrm{HA}$ values obtained by the direct $\mathrm{DAB}$ method. In the equation correlation coefficient, $r$, was found to be 0.999 .

5) Comparison between the value of urinary $H A$ measured by the direct $D A B$ method and that by the improved direct BSC method.

Sixteen urine samples from workers exposed to toluene or $\mathrm{m}$-xylene were analyzed by the improved direct BSC method and by the direct DAB method. The regression 


\section{OGATA AND T. HOBARA}

equation between $\mathrm{HA}$ value obtained by the direct $\mathrm{DAB}$ method $(\mathrm{X})$ and that by the improved direct BSC method (Y) was expressed as $\mathrm{Y}=1.08 \mathrm{X}+0.02$. Correlation coefficient, $r$, was found to be 0.981 .

6) Comparison between the value of urinary $H A$ measured by $H L C$ and that by the direct $D A B$ method.

Ten urine samples from persons without exposure to thinner were analyzed by the direct $\mathrm{DAB}$ method and by HLC. The regression equation between HA value obtained by the direct $\mathrm{DAB}$ method $(\mathrm{X})$ and that by the $\mathrm{HLC}(\mathrm{Y})$ was expressed as $\mathrm{Y}=0.63 \mathrm{X}$ +0.076 . Correlation coefficient, $r$, was found to be 0.85 .

7) Thin-layer chromatography.

Method of thin-layer chromatography was applied to confirm whether the DABpyridine reaction with $\mathrm{HA}$ was specific or not. Except for the section corresponding to $\mathrm{HA}$, any clear coloured section with DAB-pyridine was not observed in the sections scratched at $1 \mathrm{~cm}$ interval from the original line to front on the thin-layer chromatography of urine sample from workers exposed to toluene. The absorption spectra corresponding to $\mathrm{HA}$ are shown in Fig. 4. Since only the section corresponding to HA was coloured with DAB-pyridine as shown in the figure, the DAB-pyridine method was considered to be specific to HA.

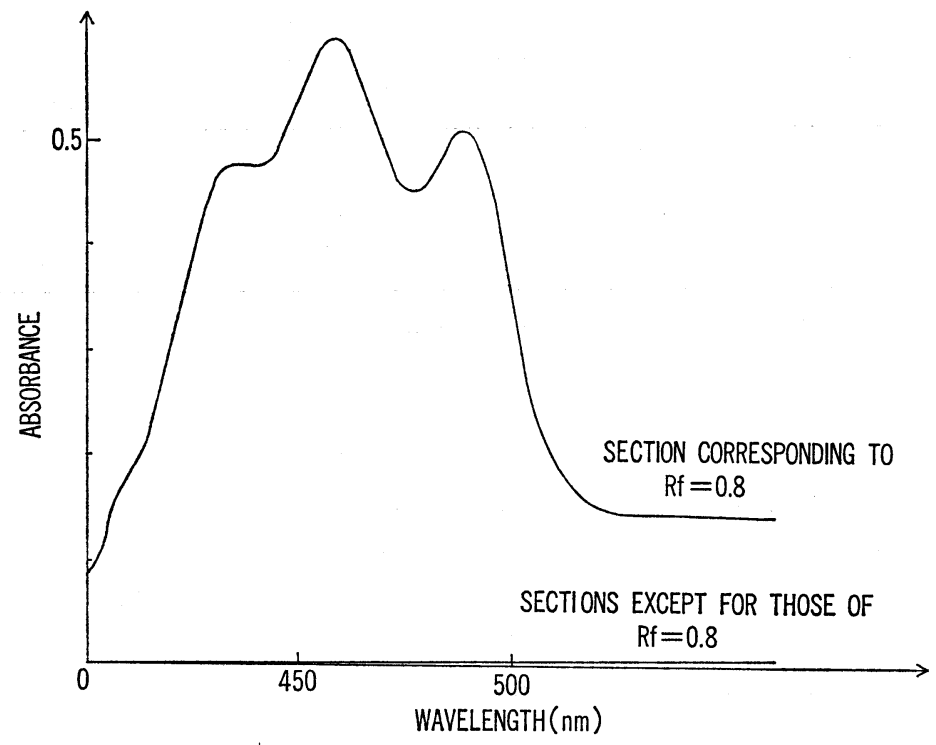

Fig 4. Absorption spectra of the sections on thin-layer chromatogram. Each section was colored according to the DAB. pyridine method. Chromatography was performed on the urine of workers exposed to toluene.

8) Normal value of urinary excretion of $H A$.

Urinary HA was measured on 33 normal persons by the direct DAB method. The 


\section{DIRECT COLORIMETRIC METHOD OF HIPPURIC ACID}

result of distribution of urinary HA was illustrated in Fig. 5. As shown in the figure, the distribution was found to be a type of logarithmic normal one. Therefore, the following calculation was made for the values obtained. The mean value $(\mathrm{m})$, the value of standard deviation (SD), the mean value plus standard deviation $(m+S D)$ and the upper side of rejection limit at 5\% level (rejection limit) of logarithmic converted values were $2.53(\mathrm{~m}), 0.122(\mathrm{SD}), 2.652(\mathrm{~m}+\mathrm{SD})$ and 2.826 (rejection limit) respectively. And the actual concentrations (antilog) of the values mentioned above, excepting the standard deviation were $340 \mu \mathrm{g} / \mathrm{ml}(\mathrm{m}), 450 \mu \mathrm{g} / \mathrm{ml}(\mathrm{m}+\mathrm{SD})$ and $607 \mu \mathrm{g} / \mathrm{ml}$ (rejection limit) respectively.

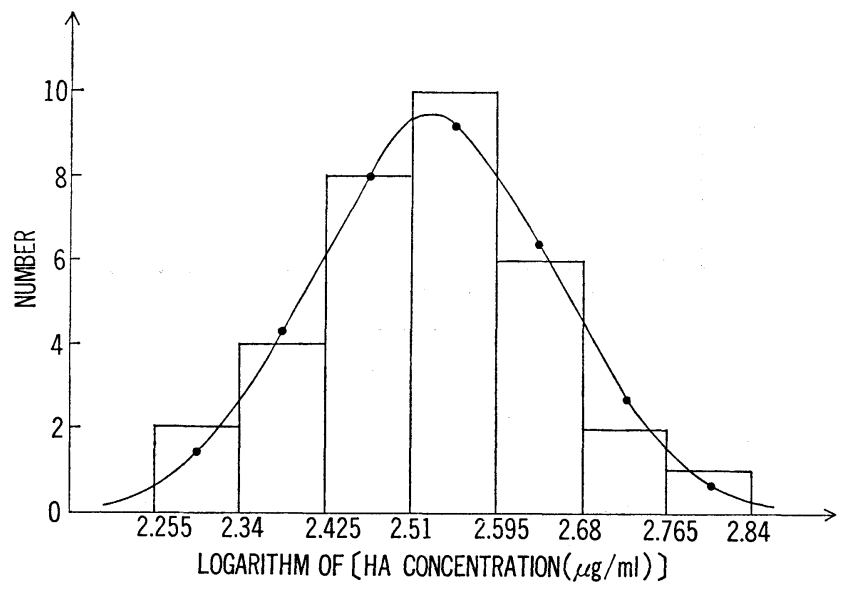

Fig. 5. Distribution curve of urinary HA concentration of normal persons.

9) Urine specimens of workers using thinner in a shipbuilding yard (Fig. 6).

Urine samples from six workers using thinner in a shipbuilding yard were examined. Samples were collected three times a day, before, during and after the work. The thinner used in spraying work contained toluene and m-xylene and their concentrations in air were about $1.1 \mathrm{ppm}, 26.5 \mathrm{ppm}$, respectively, but p-xylene was not detected on Monday. ${ }^{18)}$ These workers inhaled the thinner through taking mask, and glycine conjugates were detected in their urine by the direct $\mathrm{DAB}$ method. The examination results of the urinary concentration of glycine conjugates were drawn in Fig. 6. In this case, average concentration of toluene absorbed was assumed to be $0.8 \mathrm{ppm}$, on Monday and that of m-xylene was $14.4 \mathrm{ppm}$ from the calculation of amounts of urinary HA and $\mathrm{m}$ HA by high performance liquid chromatography. 


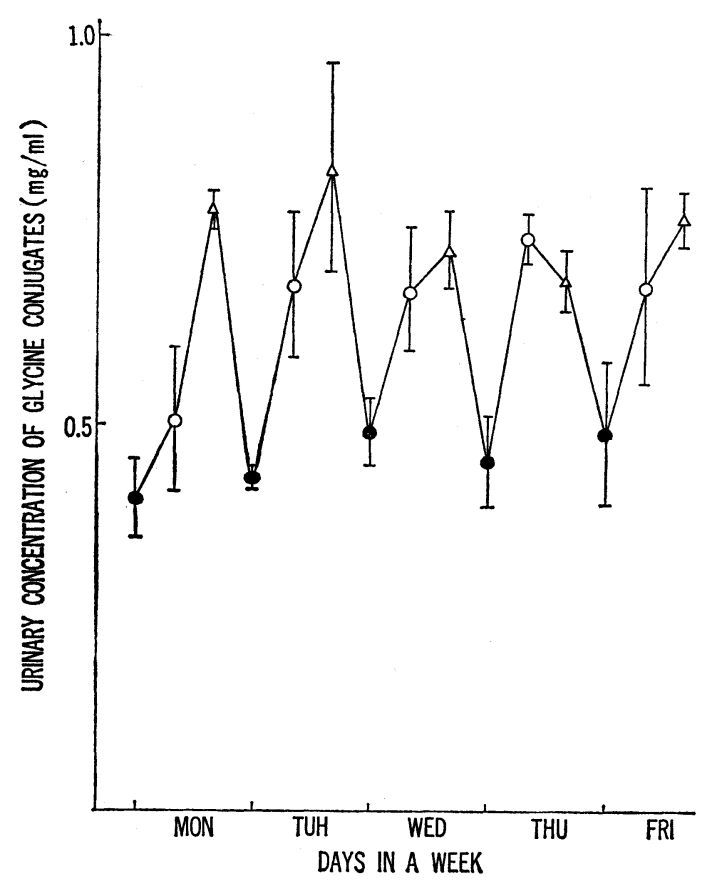

Fig. 6. Average variation of the urinary concentration of glycine conjugates in six workers on each day in a week. The workers were employing in painting in a shipbuilding yard (mean $\pm \mathrm{SEM}$ ).

\section{Discussion}

HA is excreted in the urine of persons exposed to toluene, and m-xylene and their quantitative determination is necessary for estimating the average amount of toluene inhaled by persons in such industries especially in painting or spraying works.

The colorimetric method for determination of HA, presented in this paper, is simpler and superior on the reproducibility and recovery than the direct BSC method or the extraction-DAB method.

Namely, the new direct DAB colorimetric method gave a satisfactory coefficient variation of $1.3-2.7 \%$ and recovery rate of $101.5-104.8 \%$ when urine contained about $0.2-2.0 \mathrm{mg}$ HA per $\mathrm{ml}$. Moreover, our new method has similar analytical sensitivity to both the direct BSC method and the extraction DAB method.

Small amount of water shows only slight decrease of optical density at $460 \mathrm{~nm}$ in the new direct $\mathrm{DAB}$ method as described previous paper. ${ }^{13)}$ Since only $0.02 \mathrm{ml}$ of urine is used in this method, and moreover in consideration of the simple procedures of the method and the other superiority described above, the new direct DAB method will be useful for the determination of $\mathrm{HA}$ and other glycine conjugates.

The coloured substance by the DAB method may be, 2-phenyl-4-(p-dimethylamino- 


\section{DIRECT COLORIMETRIC METHOD OF HIPPURIC ACID}

benzol) oxazol-5-one, which was synthesized by Schueler et al, ${ }^{14)}$ Gaffney et al,,3) and Ohmori and Ogata et al. ${ }^{13)}$

The absorption spectrum of 2-phenyl-4-oxazol-5-one was the same with that formed from authentic HA or urinary HA by the direct DAB method.

In this paper, the results obtained by the direct $\mathrm{DAB}$ method were compared with those obtained by the other methods such as HLC, BSC and extraction DAB method. The values obtained by HLC method with HA were found to be $86 \%$ of this method. The recovery rate of direct $\mathrm{DAB}$ method is about $100 \%$. The values determined by direct BSC method indicated $113 \%$ and by the extraction DAB method were $90 \%$ of this method. Therefore, this method is most suitable for colorimetric determination of HA. Experiment on discrepancy between HLC and colorimetric method will be carried out in the near future. Finally, it must be pointed out that the new DAB method can be applied only when HA on MHAs exists alone in urine. When both HA and MHAs exist in urine, this method gives a value of rough estimation.

As m-MHA has a similar absorption curve to HA, and the values of molar extinction coefficient of m-MHA and HA nearly the same and absorbance ratio of $\mathrm{HA}$ to MHA, when their concentrations are expressed as $\mathrm{mg} / \mathrm{ml}$, is found to be 1:0.98. Molar extinction coefficient of $\mathrm{p}$ - and o-MHA are lower, comparing to HA or m-MHA. A mixed solution of these compounds, therefore, should be first separated by paper or thin-layer chromatography, ${ }^{10)}$ and then the spots dissolved in water should be extracted with ether after drying. Then, the new DAB method should be applied. The details of procedure in repect of this mixed system will be described in subsequent papers.

\section{ACKNOWLEDGEMENT}

The authors wish to express deep thanks to Professor Tsunemi Sakai* for his interest in this work.

\section{REFERENCE}

1) Bamess, L. A., Morrow, III. G., Nocho, R.E. and Maresca, R. A. (1970). Clin. Chem. (WinstonSalem, N. C.) 16. 20.

2) Teuchy, H. and Van. Sumere, C.F. (1969). Clin. Chem. Acta. 25. 79.

3) Gaffney, G. W., Schreier, K., Diferrante, N. and Altman, K. I. (1954). J Biol. Chem. 206. 695.

4) Ellman, G. L., Burkhalter, A. and La Don, J. (1961). J. Lab. Clin. Med. 57. 813.

5) Coward, R.F. and Smith, P. (1969). J. Chromatogr. 45. 230.

6) Langenbenk, U. and Seegmiller, J.E. (1973). J. Chromatogr. 80. 81.

7) Verma, M. L. and Srivastava, R. K. (1969). Microchem. J. 14. 396.

8) Bridges, J. W., French, M.R., Smith, R. L. and Williams. R. T, (1970). Biochem. J. 118. 47.

* Department of Public Health, Yamaguchi University School of Medicine, Ube, Japan. 


\section{OGATA AND T. HOBARA}

9) Umberger, C. J. and Fiorese, F. F. (1963). Clin. Chem. (Winston-Salem. N. C.) 9. 91.

10) Ogata, M., Tomokuni, K. and Takatsuka. Y. (1969). Brit. J. Ind. Med. 26. 330.

11) Tomoknni, K. and Ogata, M. (1972). Clini. Chem. 18. 349.

12) Ogata, M. and Sugihara, R. (1977). Acta. Med. Okayama. 31. 235. (in Japanese)

13) Ohmori, S., Ikeda, M., Kira, S. and Ogata. M, (1977). Anal. Chem. 49. 1949.

14) Hobara, T. and Ogata, M. (1978). Okayama Igakkai Zasshi. 90. 1467.

15) Ogata, M. and Sugihara, R. (1978). Nippon Sangyou. Eisei. Gakkai. 51. 416. (in Japanese)

16) Ogata, M., Sugiyama, K. et al (1962). Acta. Medica. Okayama. 16. 283.

17) Norichica, K., Kira, S. and Ogata, M. (1979). Jap. J. Ind. Health. 21. 264.

18) Hobara, T. and Ogata, M. (1978). Okayama Igakkai Zasshi. 90. 1461. (in Japanese) 